\title{
Clinical potential of nintedanib for the second- line treatment of advanced non-small-cell lung cancer: current evidence
}

This article was published in the following Dove Press journal:

Lung Cancer: Targets and Therapy

I September 2014

Number of times this article has been viewed

\section{Sacha I Rothschild}

Department of Internal Medicine, Medical Oncology, University Hospital Basel, Basel, Switzerland
Correspondence: Sacha I Rothschild Department of Internal Medicine, Medical Oncology, University Hospital Basel, 4 Petersgraben, Basel 403I, Switzerland

Tel +4I 6I 2655074

Fax +4I 6I 2655316

Email sacha.rothschild@usb.ch

\begin{abstract}
The therapeutic landscape in non-small-cell lung cancer (NSCLC) is changing. The description of molecular alterations leading to NSCLC carcinogenesis and progression (so-called oncogenic driver mutations) and the development of targeted agents interfering with the tumorpromoting intracellular signaling pathways have improved the outcome for many patients with advanced/metastatic NSCLC. However, many patients with stage IV NSCLC do not have one of the targetable predictive biomarkers, and are therefore in need of classical chemotherapy. This especially applies to squamous cell cancer. A platinum-based doublet chemotherapy is the standard of care for patients with stage IV NSCLC. As second-line therapies, docetaxel, pemetrexed, and the EGFR tyrosine-kinase inhibitor erlotinib have demonstrated benefit in Phase III randomized trials. Recently, the addition of the angiokinase inhibitor nintedanib to docetaxel has proven efficacious, and is a new treatment option in the second-line setting. Preclinical and clinical data of nintedanib for the treatment of lung cancer patients are reviewed here.
\end{abstract}

Keywords: nintedanib, lung cancer, angiokinase inhibitor, VEGFR, PDGF, FGFR

\section{Introduction}

Lung cancer is associated with a high mortality rate. ${ }^{1}$ Non-small-cell lung cancer (NSCLC) is the most common subtype of lung cancer, accounting for approximately $85 \%$ of all cases. Traditional chemotherapy for advanced NSCLC has shown limited activity while producing substantial toxicity. Recent efforts in improving the therapy of NSCLC have therefore focused on the development of new treatments targeting specific signaling pathways shown to be important for tumor progression and metastasis. Angiogenesis is such an essential pathway, ${ }^{2,3}$ and has shown independent prognostic value in various malignancies. ${ }^{46}$ Angiogenesis inhibition has therefore been intensively investigated, and has shown significant antitumor activity in various tumors. ${ }^{7,8}$

VEGF promotes endothelial cell migration and proliferation, and is therefore a key factor of angiogenesis in normal and cancer tissue. There are three different receptors for VEGF: VEGFR-1, VEGFR-2, and VEGFR-3. However, the biological effects of VEGF are mediated by VEGFR-1 and VEGFR-3, whereas VEGFR-2 has been shown to have a primary role in endothelial cell activation. VEGF is expressed in most cancers, including lung cancer. ${ }^{9}$ Elevated VEGF levels are associated with higher grade and poorer differentiation of tumors, and result in a worse outcome. ${ }^{10-12}$

PDGFR also has a role in promoting angiogenesis, tumor growth, and metastasis. ${ }^{13}$ Several PDGFR tyrosine kinases are expressed on endothelial cells and pericytes. They control the survival of endothelial cells and pericyte-endothelial cell contact. ${ }^{14,15}$ PDGFR activation leads to cell migration and proliferation, as well as angiogenesis. ${ }^{16,17}$ 
FGF signaling is mediated by FGFRs. FGF signaling contributes to tissue homeostasis, tissue repair, angiogenesis, and inflammation. ${ }^{18}$ The FGFR tyrosine kinase is involved in angiogenesis, cell proliferation, and survival. ${ }^{17,19}$

A combined inhibition of several pathways involved in angiogenesis might be rational, due to the fact that tumor cells have the ability to escape the sustained inhibition of VEGF by regulating proangiogenic factors, such as PDGF and FGF. ${ }^{14,20-22}$

\section{Antiangiogenic treatment in lung cancer}

Bevacizumab was the first approved drug targeting angiogenesis. ${ }^{23}$ Bevacizumab blocks VEGF-A, and is currently approved combined with chemotherapy in various solid tumors, including nonsquamous lung cancer. Among 215 patients receiving bevacizumab monotherapy, the most common grade 3 (G3) or G4 toxicities were hypertension (in 12 patients [5.6\%]), proteinuria (in nine patients [4.2\%]), fatigue (in eleven patients [5.1\%]), and dyspnea (in 12 patients [5.6\%]). ${ }^{24}$ In patients with squamous NSCLC, severe bleedings have been described with bevacizumab, but also with other antiangiogenic drugs. ${ }^{25,26}$ Bevacizumab was approved in 2004 in combination with a platinumbased chemotherapy in the first-line setting in patients with nonsquamous NSCLC based on two randomized Phase III trials. In an Eastern Cooperative Oncology Group (ECOG) trial, 4,599 trial patients were randomized between carboplatin/paclitaxel alone and the same chemotherapy combination with bevacizumab. ${ }^{24}$ The addition of bevacizumab significantly improved overall survival (OS) (median 12.3 versus 10.3 months, hazard ratio [HR] 0.79; $P=0.03$ ). The Avastin in Lung Cancer (AVAiL) trial randomized patients to either cisplatin/gemcitabine alone or the same chemotherapy in combination with bevacizumab in two different dosages. ${ }^{27}$ Both dosages significantly improved progression-free survival (PFS), but failed to improve OS. ${ }^{28}$

Ramucirumab is a human $\mathrm{IgG}_{1}$ monoclonal antibody specifically binding to the extracellular domain of VEGFR-2. The REVEL trial randomized 1,253 patients progressing after one prior platinum-based doublet chemotherapy to docetaxel plus ramucirumab or docetaxel plus placebo. ${ }^{29,30}$ This study showed a significant prolongation of the primary end point - OS (median OS 10.5 versus 9.1 months, HR $0.857 ; P=0.0235$ ). OS was improved in nonsquamous cell carcinoma (median OS 11.1 versus 9.7 months, HR 0.83), as well as in squamous cell carcinoma (median OS 9.5 versus 8.2 months, HR 0.88).
The overall response rate for the whole study population was $22.9 \%$ versus $13.6 \%(P<0.001)$ and median PFS was 4.5 versus 3.0 months (HR $0.762, P<0.0001$ ).

Ramucirumab also showed clinical benefit in patients pretreated with bevacizumab; $14 \%$ and $14.7 \%$ of patients had had prior bevacizumab. Patients in the ramucirumab group had more bleeding or hemorrhage events of any grade ( $29 \%$ versus $15 \%$ ), although rates of G3 or worse events were much the same.

In contrary to monoclonal antibodies, small molecules inhibit tyrosine kinases within specific signaling pathways. Sorafenib is a multikinase inhibitor targeting VEGFR-2, VEGFR-3, PDGFR, RAF, and c-Kit. ${ }^{31}$ Sorafenib was investigated in two randomized Phase III trials (ESCAPE, Evaluation of Sorafenib, CArboplatin and Paclitaxel Efficacy in NSCLC; ${ }^{26}$ NExUS, NSCLC research Experience Utilizing Sorafenib ${ }^{32}$ ) in combination with chemotherapy. Neither trial showed a benefit in outcome for patients treated with sorafenib. In both trials, a similar rate of severe bleeding events in patients with squamous cell carcinoma, as with bevacizumab, was described. The NExUS trial was amended, and patients with squamous cell carcinoma were excluded from the trial after the toxicity results of the ESCAPE trial were published. ${ }^{32}$ In the BATTLE trial, sorafenib demonstrated clinical activity in NSCLC, especially with wild-type EGFR and with a specific gene signature. ${ }^{33}$ However, the MISSION trial showed that treatment with sorafenib as third- or fourthline therapy does not result in improved OS in patients with NSCLC. A post hoc biomarker analysis suggested that patients with EGFR-mutant cancers may benefit. ${ }^{34,35}$

Sunitinib inhibits VEGFR, PDGFR, c-Kit, RET, and Flt-3. Sunitinib was tested in Phase II trials in pretreated metastatic NSCLC, and showed clinical activity. ${ }^{36,37}$ Vandetanib is an inhibitor of EGFR, VEGFR, and RET. It was investigated in four randomized trials ZEST (ZACTIMA Efficacy when Studied versus Tarceva), ${ }^{38}$ ZEAL (ZACTIMA Efficacy with Alimta in Lung cancer), ${ }^{39}$ ZODIAC (ZACTIMA in combination with Docetaxel In non-smAll cell lung Cancer), ${ }^{40}$ ZEPHYR (ZACTIMA Efficacy trial for NSCLC Patients with History of EGFR-TKI and chemo-resistance). ${ }^{41}$ either as a single agent or in combination with chemotherapy. Vandetanib was not associated with an OS benefit in any of these trials. A meta-analysis of four trials evaluating vandetanib confirmed these results. ${ }^{42}$

\section{Development of nintedanib}

Nintedanib is an orally available inhibitor of VEGFR-1, -2, and -3 , FGFR-1, -2 , and -3 , and PDGFR $\alpha$ and $-\beta$ tyrosine 
kinases ("triple kinase inhibitors"). ${ }^{43}$ Nintedanib also has inhibitory activity against members of the Src family of kinases and against Flt- $3 .{ }^{43}$ Structurally, nintedanib is an indolinone derivative. It binds to the adenosine-5'-triphosphate (ATP)-binding site in the kinase domain of the aforementioned receptors, and therefore inhibits angiogenic signaling by preventing receptor dimerization. $^{43,44}$

Nintedanib has inhibited tumor growth in various preclinical models. ${ }^{43}$ Furthermore, it was shown that nintedanib could significantly enhance the cytotoxicity of doxorubicin and paclitaxel by inhibiting the function of ATP-binding cassette transporters, which are one of the main causes of multidrug resistance. ${ }^{45}$ In vivo, nintedanib demonstrates antitumor activity in different human xenograft models, including NSCLC (Calu-6), colorectal cancer (HT-29), ovarian carcinoma (SKOV-3), renal cell carcinoma (Caki-1), and prostate cancer (PAC-120). ${ }^{43}$ In tumor xenografts, nintedanib reduces tumormicrovessel density and the number of PDGFR $\beta$-expressing perivascular cells, as measured by immunohistochemistry. ${ }^{43}$

\section{Early clinical trials with nintedanib}

In the first Phase I trial, 61 patients with advanced tumors were enrolled and treated at different dose levels. ${ }^{46}$ Patients were treated for 4 weeks, followed by an interruption of 1 week. The most frequent drug-related adverse events (AEs) were mild to moderate. G3 or higher AEs with oncedaily nintedanib versus twice-daily nintedanib occurring in $>5 \%$ of patients were reversible hepatic enzyme elevation (G3 12\% versus 0; G4 4\% versus 2.8\%), aspartate aminotransferase elevation (G3 8\% versus 2.8\%), alanine aminotransferase elevation (G3 0 versus 5.6\%), $\gamma$-glutamyl transpeptidase elevation (G3 4\% versus 5.6\%), CD4 lymphocyte decrease (G3 16\% versus 5.6\%), hypertension (G3 4\% versus 0 ), diarrhea (G3 0 versus $2.8 \%$ ), nausea (G3 0 versus 5.6\%), and vomiting (G3 0 versus 2.8\%). The maximum tolerated dose (MTD) of nintedanib was determined to be $250 \mathrm{mg}$ for both once- and twice-daily dosing. In this heavily pretreated patient population, one complete response (CR) and two partial responses (PRs) were observed in patients with metastatic renal cell carcinoma and colorectal cancer. The twice-daily dosing allows for higher drug exposure without adding additional toxicity. Based on this trial showing an acceptable safety profile and first signals of clinical activity, the twice-daily dosing was recommended for further Phase II clinical trials. In an Asian population, another Phase I trial included 21 patients with advanced cancer and determined the MTD at $200 \mathrm{mg}$ twice daily. Reversible liver-enzyme elevations were the only dose-limiting toxicities (DLTs). ${ }^{47}$ In this trial, no CR or PR was described.

\section{Early trials of nintedanib in NSCLC}

In a Phase I open-label study, nintedanib was tested in combination with the folate antagonist pemetrexed in patients with recurrent metastatic NSCLC of all histological subtypes who had previously received at least one platinum-based chemotherapy. ${ }^{48}$ Patients were treated with the standard dose of pemetrexed of $500 \mathrm{mg} / \mathrm{m}^{2}$ given intravenously on day 1 and with nintedanib on days 2-21 of a 21-day cycle. The dose of nintedanib was escalated from $100 \mathrm{mg}$ given twice daily to the MTD. In this trial, the MTD of nintedanib in combination with pemetrexed was found to be $200 \mathrm{mg}$ twice daily. The most frequent DLTs were gastrointestinal disorders (86.4\%), general disorders, and administration-site conditions (76.9\%), mainly rash. One patient showed a CR, and $50 \%$ of patients showed stable disease as best overall response. No clinically relevant pharmacokinetic interactions between nintedanib and pemetrexed were observed.

Based on Phase I trials in advanced gynecological malignancies showing the feasibility of the combined treatment of nintedanib with standard doses of carboplatin and paclitaxel, ${ }^{49}$ an open-label dose-escalation study investigated the safety and tolerability of carboplatin area under the curve $6 \mathrm{mg} / \mathrm{mL} / \mathrm{min}$ and paclitaxel $200 \mathrm{mg} / \mathrm{m}^{2}$ in combination with nintedanib (starting dose $50 \mathrm{mg}$ twice-daily). This trial defined the MTD as $200 \mathrm{mg}$ twice daily. During the first treatment, cycle six DLTs occurred. These included liver-enzyme elevations, thrombocytopenia, abdominal pain, and rash. The combination treatment showed relevant activity, with seven confirmed PRs (26.9\%). Disease stabilization was described in a further ten patients. This led to a clinical benefit ratio of $84.6 \%$. No significant pharmacological interactions between chemotherapy and nintedanib were found. ${ }^{50}$

A Phase II trial evaluated two different twice daily dosages of nintedanib (150 mg [n=36] or $250 \mathrm{mg}[\mathrm{n}=37]$ as a single agent in 73 pretreated NSCLC patients with an ECOG performance status (PS) of $0-2 .{ }^{51}$ The trial reported median PFS of 6.9 weeks and OS of 21.9 weeks. The rate of disease stabilization was $46 \%$. Patients with an ECOG PS of 0-1 had median PFS of 11.6 weeks and median OS of 37.7 weeks. ${ }^{51}$ The most commonly reported AEs were nausea $(57.5 \%)$, diarrhea $(47.9 \%)$, vomiting $(42.5 \%)$, anorexia (28.8\%), abdominal pain (13.7\%), and reversible alanine aminotransferase $(13.7 \%)$ and aspartate aminotransferase elevations $(9.6 \%)$. Patients in the higher-dose group 
showed a higher rate of liver-enzyme elevations. All other toxicities were well balanced between the two groups.

\section{Phase III trials of nintedanib in NSCLC}

The LUME-Lung 1 trial included NSCLC patients independently of histological subtype, and investigated the combination of docetaxel and nintedanib. A total of 655 patients from 211 centers in 27 countries with stage IIIB/IV recurrent NSCLC progressing after first-line chemotherapy were randomized either to docetaxel $75 \mathrm{mg} / \mathrm{m}^{2}$ combined with nintedanib $200 \mathrm{mg}$ orally twice daily or docetaxel $75 \mathrm{mg} / \mathrm{m}^{2}$ combined with placebo on days 2-21 of a 3-week cycle. ${ }^{52}$ Patients were stratified by ECOG PS, histology, presence of brain metastases, and previous treatment with bevacizumab. The combination of docetaxel and nintedanib significantly improved the primary end point of PFS, with an absolute gain of 0.7 months (median 3.4 versus 2.7 months, HR 0.79; $P=0.0019$ ). Median OS was 10.1 versus 9.1 months (HR 0.94, $P=0.2720$ ). In patients with adenocarcinoma histology, nintedanib significantly improved median OS from 10.3 to 12.6 months (HR 0.83, $P=0.0359$ ). A more pronounced effect on median OS was found in patients with adenocarcinoma progressing within 9 months after initiation of first-line therapy (10.9 versus 7.9 months, HR $0.75 ; P=0.0073$ ). However, the time interval between first-line chemotherapy and progression was not a prespecified clinical end point or stratification parameter of the trial. G3 or worse adverse events that were more common in the docetaxel plus nintedanib arm than in the control arm were diarrhea, reversible increases in alanine aminotransferase, and reversible increases in aspartate aminotransferase. Toxicities of both treatment arms are summarized in Table 1. The authors concluded that the combination of docetaxel and nintedanib is an active second-line therapy in patients with advanced NSCLC previously treated with one line of platinum-based therapy, especially for patients with adenocarcinoma. Besides the previously published BR. 21 trial $^{53}$ and TAX 317 trial, ${ }^{54}$ the LUME-Lung 1 trial is the only prospective randomized Phase III trial showing a significant improvement in OS in the second-line metastatic setting. Furthermore, it is the first trial in the secondline setting combining a targeted agent with chemotherapy to show a survival benefit, with median OS longer than 1 year in patients with adenocarcinoma NSCLC versus an active comparator. However, it has to be mentioned that the absolute

Table I Overview of adverse events with a frequency $>5 \%$ classified by Common Terminology Criteria for Adverse Events (version 3.0) in all patients who received at least one dose of study drug in the LUME-Lung I study

\begin{tabular}{|c|c|c|c|c|c|c|c|c|}
\hline & \multicolumn{4}{|c|}{ Docetaxel plus nintedanib $(n=652)$} & \multicolumn{4}{|c|}{ Docetaxel plus placebo $(n=655)$} \\
\hline & All grades & G3 & G4 & G5 & All grades & G3 & G4 & G5 \\
\hline Any SAE & $34.4 \%$ & $7.4 \%$ & $7.5 \%$ & $16.4 \%$ & $31.5 \%$ & $8.9 \%$ & $6.0 \%$ & $11.8 \%$ \\
\hline Any AE & $93.6 \%$ & $21.2 \%$ & $33.7 \%$ & $16.4 \%$ & $93.0 \%$ & $21.2 \%$ & $31.3 \%$ & $11.8 \%$ \\
\hline Diarrhea & $42.3 \%$ & $6.0 \%$ & $0.5 \%$ & $0.2 \%$ & $21.8 \%$ & $2.4 \%$ & $0.2 \%$ & 0 \\
\hline Decreased neutrophils & $37.1 \%$ & $9.0 \%$ & $23.0 \%$ & 0 & $35.9 \%$ & $8.7 \%$ & $21.2 \%$ & 0 \\
\hline Fatigue & $30.4 \%$ & $4.9 \%$ & $0.6 \%$ & $0.2 \%$ & $26.9 \%$ & $3.2 \%$ & $0.5 \%$ & 0 \\
\hline Increased ALT & $28.5 \%$ & $7.8 \%$ & 0 & 0 & $8.4 \%$ & $0.9 \%$ & 0 & 0 \\
\hline Decreased WBC count & $24.5 \%$ & $11.5 \%$ & $4.9 \%$ & 0 & $24.4 \%$ & $11.1 \%$ & $4.1 \%$ & 0 \\
\hline Nausea & $24.2 \%$ & $0.8 \%$ & 0 & 0 & $18.0 \%$ & $0.9 \%$ & 0 & 0 \\
\hline Increased AST & $22.5 \%$ & $3.4 \%$ & 0 & 0 & $6.6 \%$ & $0.5 \%$ & 0 & 0 \\
\hline Decreased appetite & $22.2 \%$ & $1.1 \%$ & $0.3 \%$ & 0 & $15.6 \%$ & $1.1 \%$ & 0 & $0.2 \%$ \\
\hline Dyspnea & $19.0 \%$ & $2.1 \%$ & $0.5 \%$ & $2.3 \%$ & $16.8 \%$ & $11.5 \%$ & $3.2 \%$ & $1.8 \%$ \\
\hline Vomiting & $16.9 \%$ & $0.6 \%$ & $0.2 \%$ & 0 & $9.3 \%$ & $0.5 \%$ & 0 & 0 \\
\hline Alopecia & $16.4 \%$ & $0.2 \%$ & 0 & 0 & $18.2 \%$ & 0 & 0 & 0 \\
\hline Cough & $15.2 \%$ & $0.8 \%$ & 0 & $0.2 \%$ & $16.8 \%$ & $0.6 \%$ & 0 & 0 \\
\hline Neutropenia & $13.8 \%$ & $3.2 \%$ & $8.9 \%$ & 0 & $14.4 \%$ & $2.9 \%$ & $9.2 \%$ & 0 \\
\hline Pyrexia & $12.7 \%$ & $0.5 \%$ & $0.3 \%$ & 0 & $15.0 \%$ & $0.3 \%$ & 0 & 0 \\
\hline Decreased hemoglobin & $11.2 \%$ & $1.1 \%$ & $0.3 \%$ & 0 & $12.1 \%$ & $1.8 \%$ & $0.3 \%$ & 0 \\
\hline Constipation & $5.4 \%$ & 0 & 0 & 0 & $11.6 \%$ & $0.5 \%$ & 0 & 0 \\
\hline Asthenia & $8.9 \%$ & $2.0 \%$ & 0 & $0.3 \%$ & $9.8 \%$ & $1.2 \%$ & $0.2 \%$ & $0.2 \%$ \\
\hline Chest pain & $8.6 \%$ & $0.6 \%$ & $0.5 \%$ & $0.3 \%$ & $9.5 \%$ & $1.5 \%$ & $0.6 \%$ & 0 \\
\hline Febrile neutropenia & $7.4 \%$ & $2.6 \%$ & $4.4 \%$ & 0 & $4.9 \%$ & $2.1 \%$ & $2.6 \%$ & 0 \\
\hline Anemia & $5.4 \%$ & $0.8 \%$ & $0.3 \%$ & 0 & $7.5 \%$ & $1.2 \%$ & $0.2 \%$ & $0.2 \%$ \\
\hline Pneumonia & $5.1 \%$ & $2.1 \%$ & $0.5 \%$ & $0.5 \%$ & $5.5 \%$ & $2.1 \%$ & 0 & $1.2 \%$ \\
\hline
\end{tabular}

Note: Data from Reck et al..$^{22}$

Abbreviations: SAE, severe adverse event; ALT, alanine aminotransferase; WBC, white blood cell; AST, aspartate aminotransferase; AD, adverse event. 
Table 2 Overview of major ongoing clinical trials with nintedanib including patients with lung cancer; from http://www.clinicaltrials. gov. Accessed May 23, 2014

\begin{tabular}{|c|c|c|c|}
\hline Trial & $\begin{array}{l}\text { NCT } \\
\text { number }\end{array}$ & Description & Primary end point \\
\hline \multicolumn{4}{|l|}{ Phase I } \\
\hline BARIS & 01349296 & Nintedanib and everolimus in solid tumors & MTD, tolerability \\
\hline VENUS-I & 01684111 & $\begin{array}{l}\text { Dose-escalation trial of nintedanib in combination with intravenous } \\
\text { vinorelbine in elderly patients with advanced NSCLC }\end{array}$ & MTD \\
\hline VENUS-2 & 01683682 & $\begin{array}{l}\text { Dose escalation trial of nintedanib in combination with intravenous } \\
\text { carboplatin and vinorelbine in elderly patients with advanced NSCLC }\end{array}$ & MTD \\
\hline \multirow[t]{2}{*}{ Phase II } & $01948|4|$ & $\begin{array}{l}\text { Nintedanib in treating patients with advanced non-small-cell lung } \\
\text { cancer who have failed up to two previous chemotherapy regimens: } \\
\text { laboratory biomarker analysis }\end{array}$ & $\begin{array}{l}\text { PFS rate within the entire } \\
\text { FGFRI-amplified group }\end{array}$ \\
\hline & $0144 \mid 297$ & Nintedanib as second-line treatment for patients with small-cell lung cancer & ORR \\
\hline
\end{tabular}

Abbreviations: NCT, National Clinical Trial; NSCLC, non-small-cell lung cancer; MTD, maximum tolerated dose; PFS, progression-free survival; ORR, overall response rate; FGFRI, fibroblast growth factor receptor $\mathrm{I}$.

survival benefit in the adenocarcinoma subpopulation was only 6 weeks, and the additional toxicity is meaningful. LUME-Lung 2 (NCT00806819) investigated the efficacy and safety of nintedanib $200 \mathrm{mg}$ twice daily combined with pemetrexed compared with pemetrexed and placebo in patients with stage IIIB/IV or recurrent nonsquamous NSCLC after relapse or failure of first-line chemotherapy. Based on the results of a preplanned futility analysis of investigator-assessed PFS, conducted by an independent data-monitoring committee, recruitment was halted early after 713 of 1,300 planned patients had enrolled and ongoing patients were unblinded, as the analysis suggested that the study was futile and that the primary end point of centrally assessed PFS would likely not be met. However, it was shown that the primary end point of PFS was significantly improved in the experimental arm (median PFS 4.4 versus 3.6 months, HR $0.83 ; P=0.0435) .{ }^{55}$ The overall response rate was comparable ( $9.1 \%$ versus $8.3 \%$ ), and OS was not significantly different (median OS 12.2 versus 12.7 months, HR 1.03; $P=0.7921$ ). Overall, there was a higher incidence of $\mathrm{G} 3 / 4$ adverse events in the nintedanib plus pemetrexed arm than the placebo plus pemetrexed arm $(58.5 \%$ versus 42.3\%). However, nintedanib plus pemetrexed was not associated with an increase in serious AEs $(30.0 \%$ versus $32.8 \%$ ). Table 2 provides an overview on current clinical trials evaluating nintedanib in patients with lung cancer.

\section{Conclusion}

Tumor angiogenesis is a complex and crucial mechanism in tumorigenesis and tumor progression. Inhibition of angiogenesis by targeting the VEGF pathway has resulted in improved patient survival in different solid tumors. However, VEGF is not the only player in the angiogenesis signaling, and various resistance mechanisms to VEGF-targeting agents have been described. ${ }^{56}$ Therefore, novel treatment approaches are urgently needed. This might be possible by combining antiangiogenic drugs with substances targeting other important signaling pathways or by the discovery of novel compounds targeting angiogenesis by multiple pathways.

Compared to other angiogenesis inhibitors, nintedanib has a different profile of targeting VEGFR, PDGFR, and FGFR. It also has a distinct pharmacokinetic profile. ${ }^{43}$ Nintedanib seems to be very well tolerated with no severe bleeding, which makes it an interesting angiogenesis inhibitor, especially in patients with squamous cell histology. However, results from the first randomized Phase III trial (LUME-Lung 1) showed higher efficacy in adenocarcinoma patients. ${ }^{52}$

In future studies, it will be important to do correlative biomarker analyses to establish predictive markers for response and elucidate mechanisms of resistance. The discovery of specific patient populations that will derive benefit from nintedanib or other antiangiogenic drugs is an unmet need in NSCLC treatment.

\section{Disclosure}

SIR has received honoraria from BMS, Boehringer-Ingelheim, Eli-Lilly, Hoffmann-La Roche, Merck, Pfizer, and SanofiAventis for lectures and participation on advisory boards.

\section{References}

1. Siegel R, Naishadham D, Jemal A. Cancer statistics, 2013. CA Cancer J Clin. 2013;63(1):11-30.

2. Hanahan D, Folkman J. Patterns and emerging mechanisms of the angiogenic switch during tumorigenesis. Cell. 1996;86(3):353-364.

3. Kerbel RS. Antiangiogenic therapy: a universal chemosensitization strategy for cancer? Science. 2006;312(5777):1171-1175.

4. Kreuter M, Kropff M, Fischaleck A, et al. Prognostic relevance of angiogenesis in stage III NSCLC receiving multimodality treatment. Eur Respir J. 2009;33(6):1383-1388. 
5. Meert AP, Paesmans M, Martin B, et al. The role of microvessel density on the survival of patients with lung cancer: a systematic review of the literature with meta-analysis. Br J Cancer. 2002;87(7):694-701.

6. Weidner N. Intratumor microvessel density as a prognostic factor in cancer. Am J Pathol. 1995;147(1):9-19.

7. Jain RK. Normalizing tumor vasculature with anti-angiogenic therapy: a new paradigm for combination therapy. Nat Med. 2001;7(9): 987-989.

8. Giaccone $\mathrm{G}$. The potential of antiangiogenic therapy in non-small cell lung cancer. Clin Cancer Res. 2007;13(7):1961-1970.

9. Carmeliet P. VEGF as a key mediator of angiogenesis in cancer. Oncology. 2005;69 Suppl 3:4-10.

10. Bremnes RM, Camps C, Sirera R. Angiogenesis in non-small cell lung cancer: the prognostic impact of neoangiogenesis and the cytokines VEGF and bFGF in tumours and blood. Lung Cancer. 2006;51(2): 143-158.

11. Ito H, Oshita F, Kameda Y, et al. Expression of vascular endothelial growth factor and basic fibroblast growth factor in small adenocarcinomas. Oncol Rep. 2002;9(1):119-123.

12. Volm M, Koomagi R, Mattern J. PD-ECGF, bFGF, and VEGF expression in non-small cell lung carcinomas and their association with lymph node metastasis. Anticancer Res. 1999;19(1B):651-655.

13. Faivre S, Djelloul S, Raymond E. New paradigms in anticancer therapy: targeting multiple signaling pathways with kinase inhibitors. Semin Oncol. 2006;33(4):407-420.

14. Cao Y, Cao R, Hedlund EM. Regulation of tumor angiogenesis and metastasis by FGF and PDGF signaling pathways. J Mol Med (Berl). 2008;86(7):785-789.

15. Erber R, Thurnher A, Katsen AD, et al. Combined inhibition of VEGF and PDGF signaling enforces tumor vessel regression by interfering with pericyte-mediated endothelial cell survival mechanisms. FASEBJ. 2004;18(2):338-340.

16. Shih AH, Holland EC. Platelet-derived growth factor (PDGF) and glial tumorigenesis. Cancer Lett. 2006;232(2):139-147.

17. Beenken A, Mohammadi M. The FGF family: biology, pathophysiology and therapy. Nat Rev Drug Discov. 2009;8(3):235-253.

18. Lim SM, Kim HR, Shim HS, Soo RA, Cho BC. Role of FGF receptors as an emerging therapeutic target in lung squamous cell carcinoma. Future Oncol. 2013;9(3):377-386.

19. Presta M, Dell'Era P, Mitola S, Moroni E, Ronca R, Rusnati M. Fibroblast growth factor/fibroblast growth factor receptor system in angiogenesis. Cytokine Growth Factor Rev. 2005;16(2):159-178.

20. Rosen LS. Clinical experience with angiogenesis signaling inhibitors: focus on vascular endothelial growth factor (VEGF) blockers. Cancer Control. 2002;9(Supp1 2):36-44.

21. Bergers G, Song S, Meyer-Morse N, Bergsland E, Hanahan D. Benefits of targeting both pericytes and endothelial cells in the tumor vasculature with kinase inhibitors. J Clin Invest. 2003;111(9): $1287-1295$

22. Casanovas O, Hicklin DJ, Bergers G, Hanahan D. Drug resistance by evasion of antiangiogenic targeting of VEGF signaling in late-stage pancreatic islet tumors. Cancer Cell. 2005;8(4):299-309.

23. Ferrara N, Hillan KJ, Gerber HP, Novotny W. Discovery and development of bevacizumab, an anti-VEGF antibody for treating cancer. Nat Rev Drug Discov. 2004;3(5):391-400.

24. Sandler A, Gray R, Perry MC, et al. Paclitaxel-carboplatin alone or with bevacizumab for non-small-cell lung cancer. $N$ Engl J Med. 2006;355(24):2542-2550.

25. Herbst RS. Toxicities of antiangiogenic therapy in non-small-cell lung cancer. Clin Lung Cancer. 2006;8 Suppl 1:S23-S30.

26. Scagliotti G, Novello S, von Pawel J, et al. Phase III study of carboplatin and paclitaxel alone or with sorafenib in advanced non-small-cell lung cancer. J Clin Oncol. 2010;28(11):1835-1842.

27. Reck M, von Pawel J, Zatloukal P, et al. Phase III trial of cisplatin plus gemcitabine with either placebo or bevacizumab as first-line therapy for nonsquamous non-small-cell lung cancer: AVAil. J Clin Oncol. 2009;27(8):1227-1234.
28. Reck M, von Pawel J, Zatloukal P, et al. Overall survival with cisplatingemcitabine and bevacizumab or placebo as first-line therapy for nonsquamous non-small-cell lung cancer: results from a randomised phase III trial (AVAiL). Ann Oncol. 2010;21(9):1804-1809.

29. Garon EB, Ciuleanu TE, Arrieta O, et al. Ramucirumab plus docetaxel versus placebo plus docetaxel for second-line treatment of stage IV non-small-cell lung cancer after disease progression on platinum-based therapy (REVEL): a multicentre, double-blind, randomised phase 3 trial. Lancet. Epub June 2, 2014.

30. Perol M, Ciuleanu TE, Arrieta O, et al. REVEL: a randomized, doubleblind, phase III study of docetaxel (DOC) and ramucirumab (RAM; IMC-1121B) versus DOC and placebo (PL) in the second-line treatment of stage IV non-small cell lung cancer (NSCLC) following disease progression after one prior platinum-based therapy. J Clin Oncol. 2014;32(Suppl 5):LBA8006.

31. Wilhelm SM, Carter C, Tang L, et al. BAY 43-9006 exhibits broad spectrum oral antitumor activity and targets the RAF/MEK/ERK pathway and receptor tyrosine kinases involved in tumor progression and angiogenesis. Cancer Res. 2004;64(19):7099-7109.

32. Paz-Ares LG, Biesma B, Heigener D, et al. Phase III, randomized, double-blind, placebo-controlled trial of gemcitabine/cisplatin alone or with sorafenib for the first-line treatment of advanced, nonsquamous non-small-cell lung cancer. J Clin Oncol. 2012;30(25): 3084-3092.

33. Blumenschein GR Jr, Saintigny P, Liu S, et al. Comprehensive biomarker analysis and final efficacy results of sorafenib in the BATTLE trial. Clin Cancer Res. 2013;19(24):6967-6975.

34. Paz-Ares L, Hirsh V, Zhang L, et al. Monotherapy administration of sorafenib in patients with non-small cell lung cancer: phase III, randomized, double-blind, placebo-controlled MISSION trial. Ann Oncol. 2012;23 Suppl 9):LBA33.

35. Mok TSK, Paz-Ares L, Wu YL, et al. Association between tumor EGFR and KRAS mutation status and clinical outcomes in NSCLC patients randomized to sorafenib plus best supportive care (BSC) or BSC alone: subanalysis of the phase III MISSION trial. Ann Oncol. 2012;23 Supp1 9):LBA9.

36. Socinski MA, Novello S, Brahmer JR, et al. Multicenter, phase II trial of sunitinib in previously treated, advanced non-small-cell lung cancer. J Clin Oncol. 2008;26(4):650-656.

37. Novello S, Scagliotti GV, Rosell R, et al. Phase II study of continuous daily sunitinib dosing in patients with previously treated advanced non-small cell lung cancer. Br J Cancer. 2009;101(9):1543-1548.

38. Natale RB, Thongprasert S, Greco FA, et al. Phase III trial of vandetanib compared with erlotinib in patients with previously treated advanced non-small-cell lung cancer. J Clin Oncol. 2011;29(8): 1059-1066.

39. de Boer $\mathrm{RH}$, Arrieta $\mathrm{O}$, Yang $\mathrm{CH}$, et al. Vandetanib plus pemetrexed for the second-line treatment of advanced non-small-cell lung cancer: a randomized, double-blind phase III trial. J Clin Oncol. 2011;29(8): 1067-1074.

40. Herbst RS, Sun Y, Eberhardt WE, et al. Vandetanib plus docetaxel versus docetaxel as second-line treatment for patients with advanced non-small-cell lung cancer (ZODIAC):a double-blind, randomised, phase 3 trial. Lancet Oncol. 2010;11(7):619-626.

41. Lee JS, Hirsh V, Park K, et al. Vandetanib versus placebo in patients with advanced non-small-cell lung cancer after prior therapy with an epidermal growth factor receptor tyrosine kinase inhibitor: a randomized, double-blind phase III trial (ZEPHYR). J Clin Oncol. 2012;30(10):1114-1121.

42. Qi WX, Tang LN, He AN, Shen Z, Yao Y. The role of vandetanib in the second-line treatment for advanced non-small-cell-lung cancer: a meta-analysis of four randomized controlled trials. Lung. 2011;189(6): 437-443.

43. Hilberg F, Roth GJ, Krssak M, et al. BIBF 1120: triple angiokinase inhibitor with sustained receptor blockade and good antitumor efficacy. Cancer Res. 2008;68(12):4774-4782. 
44. Roth GJ, Heckel A, Colbatzky F, et al. Design, synthesis, and evaluation of indolinones as triple angiokinase inhibitors and the discovery of a highly specific 6-methoxycarbonyl-substituted indolinone (BIBF 1120). J Med Chem. 2009;52(14):4466-4480.

45. Xiang QF, Wang F, Su XD, et al. Effect of BIBF 1120 on reversal of ABCB1-mediated multidrug resistance. Cell Oncol (Dordr). 2011;34(1):33-44.

46. Mross K, Stefanic M, Gmehling D, et al. Phase I study of the angiogenesis inhibitor BIBF 1120 in patients with advanced solid tumors Clin Cancer Res. 2010;16(1):311-319.

47. Okamoto I, Kaneda H, Satoh T, et al. Phase I safety, pharmacokinetic, and biomarker study of BIBF 1120, an oral triple tyrosine kinase inhibitor in patients with advanced solid tumors. Mol Cancer Ther. 2010;9(10):2825-2833.

48. Ellis PM, Kaiser R, Zhao Y, Stopfer P, Gyorffy S, Hanna N. Phase I open-label study of continuous treatment with BIBF 1120, a triple angiokinase inhibitor, and pemetrexed in pretreated non-small cell lung cancer patients. Clin Cancer Res. 2010;16(10):2881-2889.

49. du Bois A, Huober J, Stopfer P, et al. A phase I open-label doseescalation study of oral BIBF 1120 combined with standard paclitaxel and carboplatin in patients with advanced gynecological malignancies. Ann Oncol. 2010;21(2):370-375.

50. Doebele RC, Conkling P, Traynor AM, et al. A phase I, open-label doseescalation study of continuous treatment with BIBF 1120 in combination with paclitaxel and carboplatin as first-line treatment in patients with advanced non-small-cell lung cancer. Ann Oncol. 2012;23(8): 2094-2102.
51. Reck M, Kaiser R, Eschbach C, et al. A phase II double-blind study to investigate efficacy and safety of two doses of the triple angiokinase inhibitor BIBF 1120 in patients with relapsed advanced non-small-cell lung cancer. Ann Oncol. 2011;22(6):1374-1381.

52. Reck M, Kaiser R, Mellemgaard A, et al. Docetaxel plus nintedanib versus docetaxel plus placebo in patients with previously treated non-small-cell lung cancer (LUME-Lung 1): a phase 3, doubleblind, randomised controlled trial. Lancet Oncol. 2014;15(2): 143-155.

53. Shepherd FA, Rodrigues Pereira J, Ciuleanu T, et al. Erlotinib in previously treated non-small-cell lung cancer. $N$ Engl J Med. 2005;353(2):123-132.

54. Shepherd FA, Dancey J, Ramlau R, et al. Prospective randomized trial of docetaxel versus best supportive care in patients with non-small-cell lung cancer previously treated with platinum-based chemotherapy. J Clin Oncol. 2000;18(10):2095-2103.

55. Hanna NH, Kaiser R, Sullivan RN, et al. Lume-lung 2: a multicenter, randomized, double-blind, phase III study of nintedanib plus pemetrexed versus placebo plus pemetrexed in patients with advanced nonsquamous non-small cell lung cancer (NSCLC) after failure of first-line chemotherapy. J Clin Oncol. 2013;31 Suppl:8034.

56. Bergers G, Hanahan D. Modes of resistance to anti-angiogenic therapy. Nat Rev Cancer. 2008;8(8):592-603.
Lung Cancer: Targets and Therapy

\section{Publish your work in this journal}

Lung Cancer: Targets and Therapy is an international, peer-reviewed, open access journal focusing on lung cancer research, identification of therapeutic targets and the optimal use of preventative and integrated treatment interventions to achieve improved outcomes, enhanced survival and quality of life for the cancer patient. Specific topics coveredin the journal include: Epidemiology, detcon antion and screening; Cellular research and biomarkers; Identification of biotargets and agents with nove

\section{Dovepress}

mechanisms of action; Optimal clinical use of existing anticancer agents, including combination therapies; Radiation and surgery; Palliative care; Patient adherence, quality of life, satisfaction; Health economic evaluations. The manuscript management system is completely online and includes a very quick and fair peer-review system. Visit http://www.dovepress.com/testimonials.php to read real quotes from published authors. 